\title{
Dental lasers applications in visible wavelength operational band
}

\author{
Mahmoud M. A. Eid ${ }^{1}$, IS Amiri2,3, P Yupapin ${ }^{2,3}$, Ahmed Nabih Zaki Rashed ${ }^{4}$ \\ ${ }^{1}$ Department of Electrical Engineering, College of Engineering, Taif University, Kingdom of Saudi Arabia \\ ${ }^{2}$ Computational Optics Research Group, Advanced Institute of Materials Science, Ton Duc Thang University, \\ Ho Chi Minh City, Vietnam \\ ${ }^{3}$ Faculty of Applied Sciences, Ton Duc Thang University, Ho Chi Minh City, Vietnam \\ ${ }^{4}$ Electronics and Electrical Communications Engineering Department Faculty of Electronic Engineering, \\ Menoufia University, Egypt
}

\begin{tabular}{l} 
Article Info \\
\hline Article history: \\
Received Aug 17, 2019 \\
Revised Nov 18, 2019 \\
Accepted Dec 2, 2019 \\
\hline
\end{tabular}

\section{Keywords:}

Caries progression Charge-coupled device Image processing Storage phosphor system

\begin{abstract}
There is no doubt that radiation has many side effects in our lives, so our goal in this study is to reduce our use of radiation in the diagnosis of tooth caries, and in order to achieve this goal we used the field of optical fiber in the detection of some diseases associated with oral and dental medicine. This diagnosis was accomplished by shedding light on the teeth, to be diagnosed and creating an image that allows the doctor to examine them and determine whether there are caries or any root problems. The principle is also used to detect oral cancer, fractures, and cracks in bones. This study also allows us to detect early caries, and this method saves time because it gives the diagnosis at the same time while the patient is in the treatment unit of the dental clinic. Thus the main advantages of this method are, enable the dentist to view images on the display unit attached to the clinic in real-time, compare current photos with old photos of the same patient. Also, the dentist can create a photo archive of each tooth individually and can retrieve and compare them whenever he wants.
\end{abstract}

Copyright $(2020$ Institute of Advanced Engineering and Science. All rights reserved.

\section{Corresponding Author:}

IS Amiri,

Ton Duc Thang University,

Ho Chi Minh City, Vietnam.

E-mail: irajsadeghamiri@tdtu.edu.vn

\section{INTRODUCTION}

Dental caries which is an infectious disease in localized destruction of tooth structure, it caused by many types of bacteria such as streptococcus mutans the presence of some acids on the tooth enamel surface demineralization. Biologically, a compatible material dentinal carious lesion on both primary (deciduous) and permanent where the enamel is still contacted [1]. Diagnosing dental caries in children is so difficult due to short attention spans and lack of cooperation but, we can diagnose it by some traditional methods as diagnostic tests as (sensitivity, probing and bitewing radiography method). Alternative methods as digital radiography direct digital images may be required by two methods that are namely the charge-coupled device (CCD) and the storage phosphor system (SP). The sensitivity is the ability of the test to predict cases relating to the total number of positive cases and specificity which is the ability of the test to predict the true negative cases relating to the total of negative cases [2]. There are new methods to detect dental caries such as diagnosis of caries simply looking at a tooth to determine if caries is a presence in an inaccurate technique whose caries progression further by spreading along the enamel and dentin junction, also caries is one of the most difficult diseases to detect. Digital imaging fiber-optic transillumination (DIFOTI) uses visible light not ionizing radiation and it is approved by the food and drugs administration. Quantitative light-induced fluorescence which uses blue light ( $488 \mathrm{~nm}$ wavelength) to illuminate the tooth, which normally fluoresces a 
green color, the tooth should be dried to $15 \mathrm{sec}$ produce a more consistent reading, the carious lesion appears dark [3-4].

Image sensors, which is a type of sensor converts electrons into voltage or it's an electronic device that converts optical signal to electronic signal, which is widely used in imaging devices [5]. There are two types of image sensors such as charged coupled device (CCD) and complementary metal-oxidesemiconductor (CMOS). The best image sensor depends on the application which we use the sensor on it [6]. DIFOTI technique builds on fiber-optic transillumination (FOTI) which allows the recording of images of carious lesions during illumination [7-10]. It employs high-intensity light and has an additional greyscale camera. There are two types of mouthpieces available for use with DIFOTI, the proximal surface mouthpiece and occlusal surface mouthpiece [11].

DIFOTI has sensitivity and specificity that it is important parameters, which affect the performance of DIFOTI technique. Currently, x-ray radiation is being used in dentistry, but it has a lot of disadvantages such as its side effects on the patient, complex in operation and difficult in integration [12-15]. There is another way that is more effective than x-ray radiation [16-17]. It is found that the laser can be used in dentistry instead of x-ray radiation by a new technology called dentil and this technology depends on the light, which can be applied on the patient tooth [18-20]. How does it work? A laser light source can use to direct it toward the tooth, the light passes through some areas to the camera and the light cannot pass through other areas, which gives us dark areas [21-23]. By using a digital video camera, that makes all regions visible. This technology was called DIFOTI technology. It can make all diagnostic competence like occlusal caries, proximal caries, smooth, surface caries, secondary caries and cracks [24-25].

\section{MODEL DESCRIPTION AND RESEARCH METHOD}

Some of the results obtained from the simulation program, compared to the proper model to determine the location and percentage of caries. As shown in Figure 1 which indicates the steps that can be followed by a compiler to enable detecting caries at the image and can then surround caries at the image by a yellow rectangle or can detect that these teeth does not affect by caries and have no infection or any type of caries.

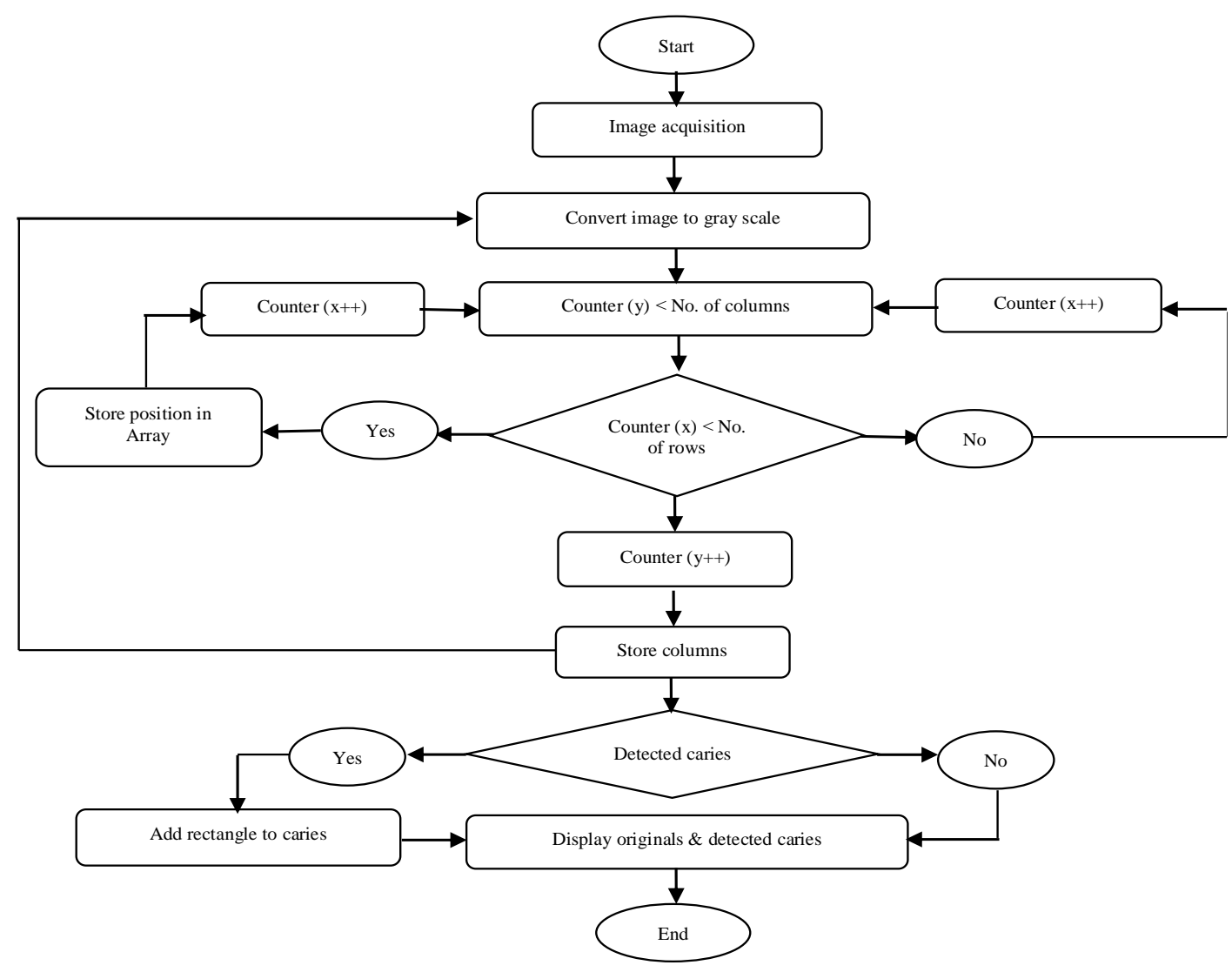

Figure 1. Flow chart of the basic steps for high biomedical image processing 
Then it display both original and modified image with caries or not, the first step is image acquisition in which the capture of the image of tooth is directly done, the image may be suffering from a lot of figuration problems that may need to be treated like shadows or blurring these issues may be solved by MATLAB filters. The next step is to convert the image from three-layer RGB (Red Green Blue) format into gray scale format, which makes detection easy. The output images are passed into two loops, also there are some if conditions that can pass some pixels value and detect the values that exceed a pre-specified threshold and store the position of both values, then the position of infected parts and not infected parts could be distinguished, after that caries could be detected and display the output.

\section{PERFORMANCE ANALYSIS WITH DISCUSSIONS}

Figure 2, shows the original image of teeth of unknown caries which will be detected in RGB format. Before applying, any effects on the image just import the image and then display it to be capable of comparing it with the gray scale image in which caries had been detected using the MATLAB environment. There are some functions that can be used to detect caries IMREAD (' $x$ ') to read the stored image from a stored database of images, $\mathrm{x}$ is the image name, IMSHOW(y) to display the image $y$, for loops and if conditions that had been used to detect the caries at the images. Figure 3 describes the image of teeth with detected caries of $(7.6893 \%)$ of the image in gray scale format, this result after passing with a lot of operations and applying many functions to detect the black colored caries in the image.

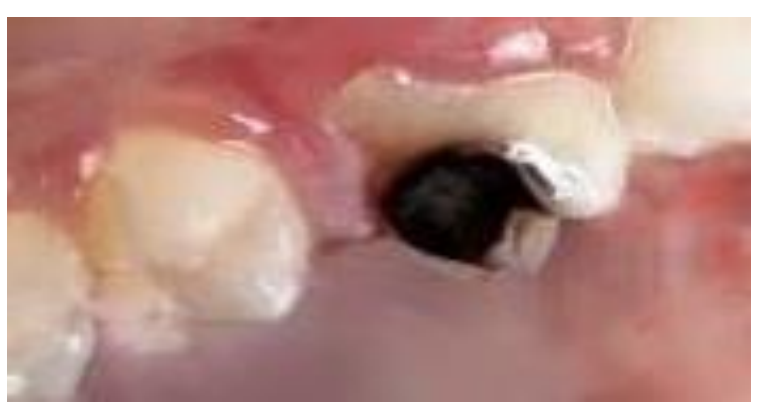

Figure 2. The original image of teeth of unknown caries

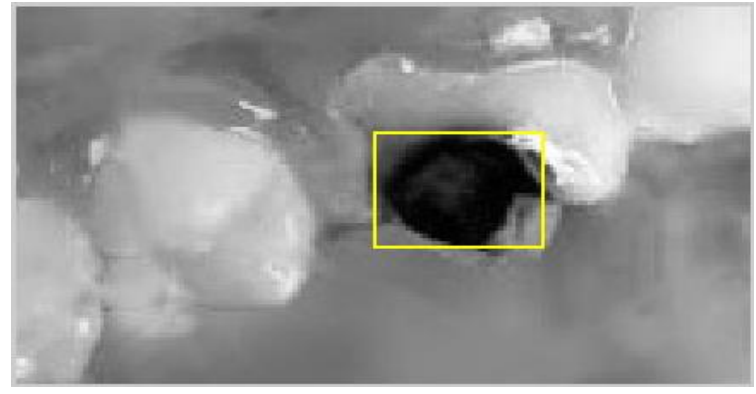

Figure 3. Image of teeth with detected caries of $(7.6893 \%)$ of the image

All detected caries at the image of teeth are surrounded by a yellow rectangle shape, by using insert shape command at MATLAB environment. There are functions that can be used to detect caries, $\operatorname{IMREAD}(\mathrm{x})$ to read the stored image from a stored database of images, $\mathrm{x}$ is the image name. IMSHOW(y) to display the image y. Also, insertShape (image, shape type, shape dimensions) used to insert a shape in the image, uigetfile refers to the user interface to get a file using GUI (Graphical User Interface). Figure 4 shows the original image of teeth of unknown caries, which is needed to be detected if it exists in RGB format before applying any effects on the image. Figure 5 describes the image of teeth with detected caries of $(0 \%)$ of the image in gray scale format after passing through a lot of operations and applying a lot of functions to detect the black colored carries in the image.

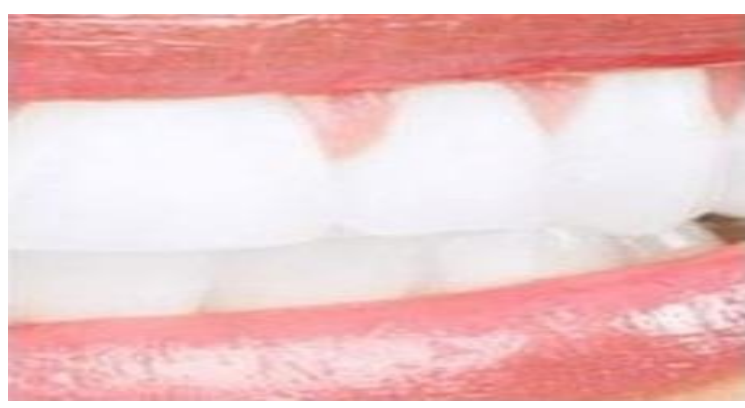

Figure 4. The Original Image of teeth of unknown caries

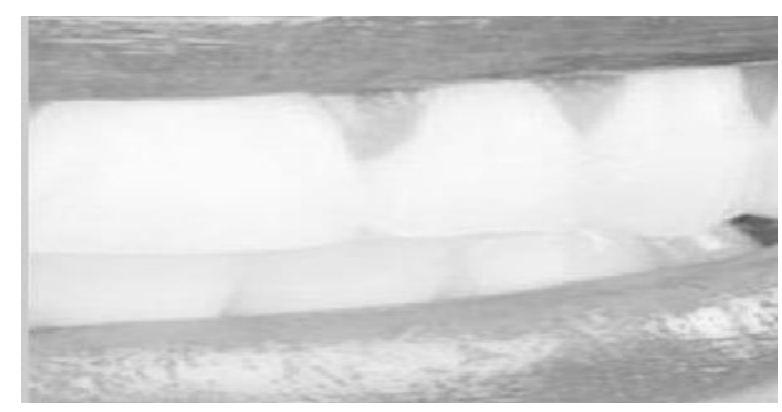

Figure 5. Image of teeth with detected caries of $(0 \%)$ of the image 
Figure 6 shows the original image of teeth of unknown caries, which is needed to be detected if it exists in RGB format before applying any effects on the image. Figure 7 describes the image of teeth with detected caries of $(32.7407 \%)$ of the image in gray scale format after passing through a lot of operations and applying a lot of functions to detect the black colored carries in the image.

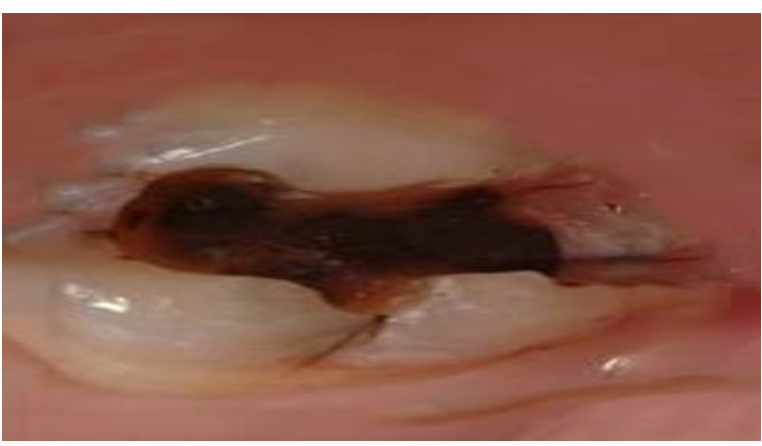

Figure 6. The Original Image of teeth of unknown caries

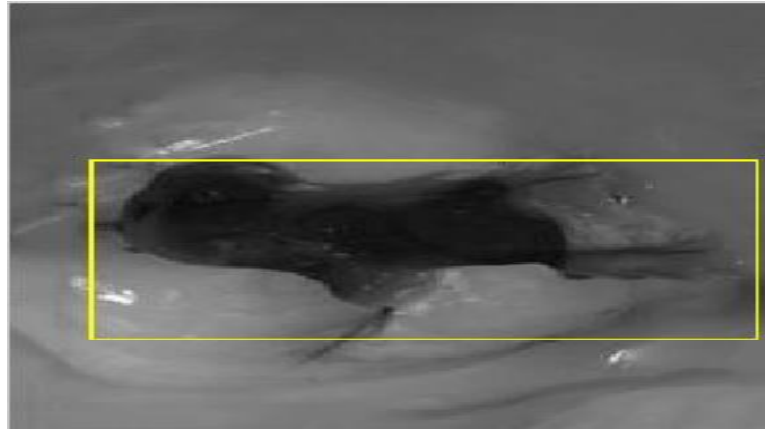

Figure 7. Image of teeth with detected caries of $(32.7407 \%)$ of the image

\section{CONCLUSION}

FOTI technique had been used as a caries detection technique, where the illumination principle is used to detect the presence of caries. There are many advantages in the case of using DIFOTI instead of radiography, the is no ionizing radiation nor film, the diagnosis has been accomplished in real-time, could detecting early lesions that may not appear to x-ray.

\section{REFERENCES}

[1] Anouk L. Post, et al., "Modeling subdiffusive light scattering by incorporating the tissue phase function and detector numerical aperture," J. Biomed. Opt., Vol. 22, article 050501, pp. 1-4, May 2017.

[2] Marc R. Reinig, et al., "Enhancing image quality in cleared tissue with adaptive optics," J. Biomed. Opt., Vol. 21, No. 12, article 121508, pp. 1-9, Dec. 2016.

[3] Ismail Hakki Baltacioglu and Kaan Orhan, "Comparison of diagnostic methods for early interproximal caries detection with near-infrared light transillumination: an in vivo study," BioMed Central, DOI: 10.1186/s12903-0170421-2, Dec. 2017.

[4] Sean T. Horan, et al., "Recovery of layered tissue optical properties from spatial frequency-domain spectroscopy and a deterministic radiative transport solver," J. Biomed. Opt., Vol. 24, No. 7, Article 071607, doi: 10.1117/1.JBO.24.7.071607, July 2019.

[5] Vijay Laxmi Kalyani and Varsha Sharma, “Optical Sensors And Their Use In Medical Field,” JMEIT, Vol. 3, No. 5, Oct. 2016.

[6] M. Karthikkumar, et al., "Extremely Low-Cost Diagnostic Bio-Sensor using CMOS Technology for Medical Applications," IOSR-JECE, Vol. 11, No. 5, pp. 65-72, Oct. 2016.

[7] A. Pretty and G. Maupomé, "A closer look at diagnosis in clinical dental practice: part 5. Emerging technologies for caries detection and diagnosis," Journal-Canadian Dental Association, vol. 70, pp. 540-541, 2004.

[8] N. N. F. Abogazalah, "Performance of near infared digital imaging transillumination for detection of non-cavitated approximal caries," 2016.

[9] C. M. Zakian, I. A. Pretty, and R. Ellwood, "Near-infared hyperspectral imaging of teeth for dental caries detection," Journal of Biomedical Optics, vol. 14, p. 064047, 2009.

[10] D. T. Zero, M. Fontana, E. A. Martínez-Mier, A. Ferreira-Zandoná, M. Ando, C. González-Cabezas, et al., "The biology, prevention, diagnosis and treatment of dental caries: scientific advances in the United States," The Journal of the American Dental Association, vol. 140, pp. 25S-34S, 2009.

[11] Howard E. Strassler, DMD; and Mark L. Pitel, "Using Fiber-Optic Transillumination as a Diagnostic Aid in Dental Practice," Compendium, Vol. 35, No. 2, pp. 80-88, Feb. 2014.

[12] J. Yang and V. Dutra, "Utility of radiology, laser fluorescence, and transillumination," Dental Clinics, vol. 49, pp. 739-752, 2005.

[13] J. Carbone, B. Hennessy, and S. Hondrum, "Investigation into use of Digital Imaging Fiber-Optic Transillumination (DIFOTI [R]) in caries detection," US Army Medical Department Journal, pp. 35-41, 2006.

[14] G. C. Jones, R. S. Jones, and D. Fried, "Transillumination of interproximal caries lesions with 830-nm light," in Lasers in dentistry X, 2004, pp. 17-22.

[15] H. Tassery, B. Levallois, E. Terrer, D. Manton, M. Otsuki, S. Koubi, et al., "Use of new minimum intervention dentistry technologies in caries management," Australian Dental Journal, vol. 58, pp. 40-59, 2013. 
[16] Marja-Liisa Laitala, et al., "Validity of Digital Imaging of Fiber-Optic Transillumination in Caries Detection on Proximal Tooth Surfaces," International Journal of Dentistry, Article ID 8289636, pp. 1-6, Oct. 2017.

[17] A' . A' stvaldsdo' ttir, et al., "Approximal Caries Detection by DIFOTI: In Vitro Comparison of Diagnostic Accuracy/Efficacy with Film and Digital Radiography," International Journal of Dentistry, Article ID 326401, pp. 1-8, Oct. 2012.

[18] Naseem Shah, et al., "Recent advances in imaging technologies in dentistry," World Journal of Radiology, Vol. 6, No. 10, pp. 794-807, Oct. 2014.

[19] Monika Machoy, et al., "The Use of Optical Coherence Tomography in Dental Diagnostics: A State-of-the-Art Review," Journal of Healthcare Engineering, Article ID 7560645, pp. 1-31, Oct. 2017.

[20] Seok Hyun Yun and Sheldon J. J. Kwok, "Light in diagnosis, therapy and surgery," Nature Biomedical Engineering, Vol. 1, No. 8, Jan. 2017.

[21] L. A. Gawad, Y. El-Sharkawy, H. Ayoub, A. F. El-Sherif, and M. F. Hassan, "Classification of dental diseases using hyperspectral imaging and laser induced fluorescence," Photodiagnosis and Photodynamic Therapy, vol. 25, pp. 128-135, 2019.

[22] N. C. van der Kaaij, M. J. Faaij, M. Jacob, and M. H. van der Veen, "The reproducibility of assessment of white spot lesions adjacent to orthodontic brackets, with a quantitative light induced fluorescence digital camera at different rotations of teeth-an in vitro study," BMC Oral Health, vol. 18, p. 209, 2018.

[23] J.-Y. Lee, E.-S. Lee, S.-M. Kang, and B.-I. Kim, "Application of quantitative light-induced fluorescence technology for tooth bleaching treatment and its assessment: An in vitro study," Photodiagnosis and Photodynamic Therapy, vol. 25, pp. 208-213, 2019.

[24] Hyung-In Yoon, et al., "Detection of proximal caries using quantitative light-induced fluorescence-digital and laser fluorescence: a comparative study," Journal of Advanced Prosthodont, Vol. 9, No. 6, pp. 432-438, Dec. 2017.

[25] Amid I Ismail, et al., "The International Caries Classification and Management System (ICCMS ${ }^{\mathrm{TM}}$ ) An Example of a Caries Management Pathway," BMC Oral Health, Vol. 12, No. 1, pp. 1-13, June 2014.

\section{BIOGRAPHIES OF AUTHORS}
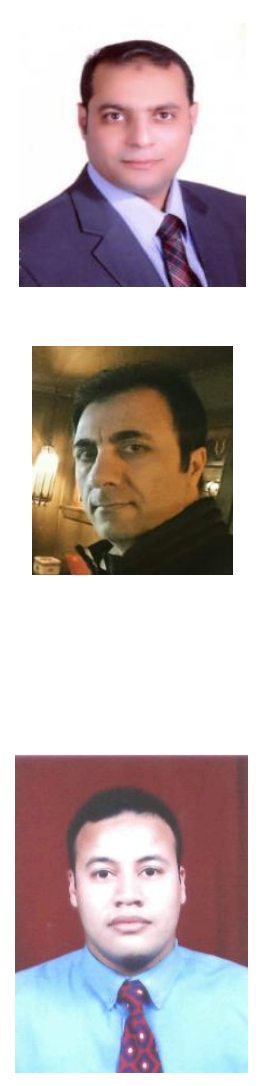

Dr. Mohamoud M. A. Eid was born in gharbiya State, Egypt, in 1977. Received the B.Sc., M.Sc., Ph.D. degrees in the Electronics Communication Engineering Department from Faculty of Electronic Engineering, Menoufia University in 2002, 2007 and 2012 respectively. Currently, He joins now the Taif University as an assistant professor in the Electrical Engineering Department, Faculty of Engineering. His scientific master science thesis has focused on optical amplifiers in optical access communication systems. His interesting research mainly focuses on optical sources, amplifiers, detectors, and sensors, optoelectronic devices.

Dr. IS Amiri has been doing research on several topics such as the optical soliton communications, laser physics, fiber lasers, fiber grating, electro-optical modulators, nanofabrications, semiconductor design and modelling, Lumerical modelling, plasmonics photonics devices, nonlinear fiber optics, optoelectronics devices using 2D materials, semiconductor waveguide design and fabrications, photolithography fabrications, E Beam lithography, quantum cryptography and nanotechnology engineering.

Assoc. Prof. Ahmed Nabih Zaki Rashed was born in Menouf city, Menoufia State, Egypt country in 23 July 1976. Received the B.Sc., M.Sc., and Ph.D. scientific degrees in the Electronics and Electrical Communications Engineering Department from Faculty of Electronic Engineering, Menoufia University in 1999, 2005, and 2010 respectively. Currently, his job carrier is a scientific lecturer in Electronics and Electrical Communications Engineering Department, Faculty of Electronic Engineering, Menoufia university, Menouf. Postal Menouf city code: 32951, EGYPT. His scientific master science thesis has focused on polymer fibers in optical access communication systems. Moreover, his scientific Ph. D. thesis has focused on recent applications in linear or nonlinear passive or active in optical networks. His interesting research mainly focuses on transmission capacity, a data rate product and long transmission distances of passive and active optical communication networks, wireless communication, radio over fiber communication systems, and optical network security and management.

He has published many high scientific research papers in high quality and technical international journals in the field of advanced communication systems, optoelectronic devices, and passive optical access communication networks. His areas of interest and experience in optical communication systems advanced optical communication networks, wireless optical access networks, analog communication systems, optical filters and Sensors. As well as he is editorial board member in high academic scientific International research Journals. Moreover, he is a reviewer member in high impact scientific research international journals in the field of electronics, electrical communication systems, 
optoelectronics, information technology and advanced optical communication systems and networks. His personal electronic mail ID (E-mail:ahmed_733@yahoo.com). His published paper under the title "High reliability optical interconnections for short range applications in high performance optical communication systems" in Optics and Laser Technology, Elsevier Publisher has achieved most popular download articles in 2013.

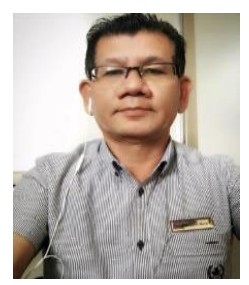

P. Yupapin received the Ph.D. degree in electrical engineering from the City, University of London, UK in 1993. He is currently the full Professor in the Computational Optics Research Group, Advanced Institute of Materials Science and member in the Faculty of Applied Sciences, Ton Duc Thang University, Ho Chi Minh City, Vietnam. His current researches of interest are nano-devices and circuits, microring resonator, soliton communication, optical motor, quantum communication, and meditation science. 